\title{
Reverse Consideration about Construction Enterprises' Ignoring Information Resource
}

\author{
Weiyue Liu
}

School of Economics and Management, Tianjin Institute of Urban Construction, Tianjin, China.

Email: a12995@163.com

Received February $15^{\text {th }}, 2013$; revised February $26^{\text {th }}, 2013$; accepted March $4^{\text {th }}, 2013$

\begin{abstract}
Through doing investigation and research of several construction enterprises in local city, the author realized the weak areas of engineering management for the construction industry. Therefore, the paper gave such a result that management status for the industry lacks process control, which seriously influences management efficiency and economic benefit of the enterprises. At present, process control of construction enterprises has such problems as the shortage of development and utilization of information resources and poor information flow process. For management and control of the process, most managers of construction enterprises do not use the scientific method and have few of concepts of scientific decision. In view of the construction project schedule, this paper discusses the influence of the information technology on process control, expounds function of the process control for improving enterprise management efficiency and analyzes utilization of information technology and information resource for improving project management. It is aimed at achieving target for strengthening management efficiency.
\end{abstract}

Keywords: Information Resource; Process Control; Management Efficiency; Construction Enterprises

\section{Introduction}

From 21st century on, China's basic construction scale is increased year by year. Investment in the construction projects has very high proportion in total social investment projects. Construction industry is one of pillar industries in the development of national economy and has influence and great pulling function to the national economy. Internationally, construction industry is one of the industries earliest for applying project management. For China, engineering management level in construction industry is not high. Many construction enterprises have weak adaptability to the market economic mode and low ability for applying the information technology. Tens of thousands of basic-level construction enterprises (contract teams) are not involved in utilizing the information technology and furthermore not affected by the advantages and conveniences for informatization to bring the construction. In the case of large size, wide scope, big investment and short time limit for our current construction field, many enterprises were not strictly in accordance with project management mode in operation and management. As result, capital, manpower, the quality and schedule and so on were seriously out of control during implementation of engineering projects, endangering the safety and quality of the projects themselves. Ensuring and improving the quality of construction project must strengthen and standardize project management for the engineering construction. The key to improve project management skills lies in choice of the tools and the methods and implementation of measures. Facing the current construction market, project management should utilize modern methods [1,2].

Along with propulsion of the national informatization strategy, business model innovates continually and the management efficiency is improved. More and more enterprises utilize the informatization to expand the business scope, to promote the management level and to increase economic benefits. With the rapid development and wide application of information technology, informationization is the trend of the development of project management. Due to the important position of the construction industry in the development of national economy, management informationization of the building industry affects the whole process of informationization of the national economy. Promoting informatization of the construction industry is imperative. In the construction industry, particularly in the basic-level construction enterprises, the information network planning technique is an important way to realize standardized management and process control. On the other hand, construction is involved in multiple markets. In a short time, it is required in switching in different engineering fields and in 
any areas far away from the command center (monitoring), construction work is run. Logistics (or goods handling) are very intricate. These characteristics determine that the building industry will have higher needs for informatization and electronic commerce than any other industries. The construction industry also will get more revenue from informatization and electronic commerce. At present, domestic building enterprises are much lower than foreign counterparts in comprehensive competition ability and the main difference is that the shortage of the management innovation. The traditional, labor-intensive construction industry can't keep up with the pace of development and cannot realize effective process control. The root cause to lead to the situation of the construction enterprises is that the informatization level is too low. This can make the enterprise competition ability insufficient, and this gap will be further widening with the increasingly open construction market. In view of schedule requirements for China's construction projects, the influence and the role of the information management in the process control for construction are discussed and analyzed in this paper, in order to improve enterprise management efficiency and operating performance [3-5].

As early as the end of last century, the ministry of construction drew up the tenth five-year plan of informatization for the state construction. The plan pointed out that the development of informationization at home and abroad brought the opportunity and the challenge for the national construction. The construction career should contribute to make a country strong and economic prosperity and must speed up the informatization itself. Based on the overall requirements of informationization of the national economy, the ministry of construction plans and organizes informatization of the state construction career which is the national construction industries widely apply information technology, develop in depth and scientifically use abundant information resources, so as to optimize industrial structure, promote the progress of science and technology in the industry, improve the work efficiency, the social efficiency and the economic efficiency, and gradually realize office automation, management modernization and decision-making scientifically. It holds interests of many experts [6-8], some of whom mentioned to apply BIM (Building Information Modeling) successfully in design stage for construction industry but poor application of BIM for construction enterprise [915]. The informatization of the state construction career will accelerate the process of modernization construction and contribute to rapid and healthy development of the national economy.

\section{Literature Reviews}

The reviewed literatures show that China construction industry is experiencing a big change in operation and management. In recent years, the construction enterprises make great contribution for our country's modernization and the construction industry has become a pillar Industry of China's economy. It is well-known fact. However, as shown in Reference [7], management status and level for the construction enterprises is not optimistic. Improving the management level of the enterprises is helpful to improve the competitiveness of them.

Through the analysis on problems for the construction enterprises in management, a lot of authors put forward some solutions for the problems, in order to improve management level of the enterprises and enhance their competitiveness.

As Yang Meifu mentioned at his paper in Reference [11], the problems related to business model and management concept for the construction enterprises are in the final analysis the enterprises' lack of information resource utilization and development.

Due to the characteristics of the production and operation of the construction industry, such as complicated procedure, strong dynamic change, a lot of data files, information management with high difficulty, etc., overall levels of information management integration of construction enterprise resources are very low. Many managers of the enterprises have not realized that enterprise informatization is a systematic engineering which is benefit to the enterprise reform, and they have inadequate understanding to the importance of enterprise informatization.

Information technology in the construction enterprises plays a more and more important role in a project implementation process, and informatization is an inevitable requirement for enterprise's survival and development so as to enhance the international competitiveness. By utilizing informatization, project management for construction leads to a success with higher efficiency and benefit. Hu Renyi [12] also pointed out that the enterprise must have risk awareness in the process to make informatization. At the same time that informatization brings high efficiency, high risk occurs due to the high investment and management reform.

Hu Renyi emphasizes that application of information technology is able to promote knowledge management for the building enterprises. In the era of knowledge economy, production, storage, transfer and use for knowledge (also including applied techniques) are closely related with information technology. So, the application of information technology has a definite link with knowledge management. In the construction enterprises, departments at all levels and various processes of project can make its sharing through the knowledge information, so as to improve efficiency and increase benefits.

At their paper titled as "BIM and RFID Assisted Life Cycle Management of Prefabricated Buildings," Li 
Tianhua etc. [15] took prefabricated buildings as an example and explained it important and necessary to implement BIM (building Information Model) in building lifecycle management (BLM). The authors pointed out that in view of characteristics of the prefabricated buildings, it is a tendency to combine BIM and RFID (radio frequency identification technology) with the construction process, in order to solve the problem that a key technology platform is lacking in the BLM. This approach helps all stakeholders create, share, exchange and manage information throughout the phases of lifecycle, and plays a positive role in promoting BIM. Application of BIM in construction will become a model for implementing informatization in construction.

Overall, our country takes the design as the leading factor in the implementation methods of prefabricated construction. However, in the design process, one lacks full consideration to the needs of the manufacture and installation. And so during the actual manufacture and installation, the design conflict appears and construction collision happens easily. Any design change, which led to waiting time and shutdown of the manufacturer and installation site, influences the progress and quality of the projects.

Therefore, in order to solve the management problem of prefabricated construction, it is imperative to coordinate the collaboration between designers and construction makers and make smooth flow ant sharing of information between parties at each stage.

\section{The Situation of Informatization Management in Construction Industry}

For more than ten years, achievements of information management have been obtained in the engineering construction field for our country. Informatization in the construction industry also has considerable development. However, in comparison with the requirements of the national informatization planning, a large gap still exists for informatization in the construction industry, mainly in narrow information application and low application level [16]. Architectural planning and designing department pays great attention to product design informatization (commonly the department uses CAD software in their business.) but the application of informatization in product database and service is not perfect; information system of real estate sales and its service units is also limited to low levels of internal use, and lacks of application of the electronic commerce and application of supply chain management. Informatization of basic-level construction enterprise is extremely backward [17], seriously constraining the development of the informationization for whole construction industry.

At present, informationization in our country construction enterprises is not popular and not being more practi- cal. Many business managers do not understand and can not completely accept such a concept as information management. They have no strategic vision and no sense of competition. They do not have planning of the enterprise informationization. The implementation of the enterprise management is still in the traditional stage, manual operation or basic means. Informationization for the building enterprises does not synchronize with society $[18,19]$.

The investigated state-owned architectural design institute (certified as class A) undertakes the designing tasks for large bridge projects, public facilities and residential projects in recent years. The design institute operates by implementing project management. Almost all of staffs are in charge of the self-governed projects. Even though equipped with some necessary professional design software, the design institute has no other management information system. CAD design results are transferred in the form of paper to construction enterprises, supervision parties and clients. Basic management for the institute is run by manual operation or by computer single operation mode.

A testing station for the building materials used for construction engineering undertakes detecting and testing tasks with a variety of rolled steels and concrete blocks. It was found by a survey that the testing station brought in an information system for test project management five years ago. The entrusted test projects can be followed up in the system from the receiving samples, sample into the warehouse, sample pretreatment, sample testing, testing data uploading, data processing, resulting reviewing to the result printing. But, since most of the operation is done by the human and sometimes operator does not timely input data, the deviation can appear between information of system and practical work. In the testing station, system operation, maintenance and updating are lack of technical support and the system data (or information) can't respond to the change of the business.

A survey to a state-owned construction group found that because its basic-level construction enterprises had no computer and networking equipment, any business of the group lied in the most primary practice: manual operation. Most of messages are conveyed by staff. Although the group executes the contracting contract for managing construction projects, monitoring for the project process, purchasing raw material, allocating tasks, energy utilizing and the equipment operating status are completely dependent on traditional manual operation or records. Statistical reports, business orders and annual performance analysis were done by single-computer processing.

In a construction site for a large construction enterprise, it was found that there were so many varieties and so huge quantity of materials and equipments. The scene materials were put orderly, but material management was 
relied on manual recording and single computer data storage. The data was not updated in time and there existed in following problems of the construction site:

1) Business process is not standard

There are no strict requirements for taking the materials and work runs with big randomness. There are no records for the quantity and type of materials needed. No one follows use and user of the materials and equipments. It often happened with a brick used alternatively as stufffed materials. It results in a shortage of some materials;

Material status was not recorded or not updated in time. Shortage or overstock of materials occurs frequently. The normal supply for materials was not provided. So, waiting for work or shutdown event happened. Especially source-unstable materials are hard supplied to the site in time. The schedule of the projects was run randomly and the project plan was implemented as expected.

2) Material management is not scientific

Materials were managed with no standardization. There is a lack of standard record and complete data with types, specifications, quality, quantity, the use status and batch and origin for the materials. The data management and intelligence analysis were not implemented by more convenient means. The out-of-stock, overstock and quality problems for materials appeared and the roots were difficultly traced back to. In addition, such problems are not avoided by current measures.

3) No measures for cost control

Almost all of operators use material and energy in no scientific methods and do not follow the principle of maximizing utilization in the material. Factitious waste and damage of material and waste of water and power frequently occur. The resource wastes severely. Besides, operators discarded construction waste randomly, causing the difficulty of recovery and recycling. This situation shows that operators have no high quality, no strong sense of responsibility and management is the lack of the cost control system.

\section{Development and Utilization of Information Resources in Project Management}

Construction enterprise is the basic unit for implementing project management. Most of the construction enterprises do their management in the traditional manual operation. Material supply and purchase, material stock and the material change in the use rely mainly on the manual record, calculation and processing. Factitious mistake are inevitable. Such an operation can also not reflect and transfer information transform. Some materials are overstock and others are of shortage. If usage of human resource, material and equipment is followed up and given feedback by lack of the strong support of information, problems in engineering projects happen unavoidably. If the problem happens, it is impossible to find causes and furthermore, there is no way to predict and avoid the potential problems and hidden troubles. The lack of information management goes to the scattered, disorderly and poor status in process management and no high efficiency for management and operation in construction enterprises.

For construction enterprises, information in management process involved in material, logistics, inventory, purchase, the progress of the projects is characterized in big quantity, wide scope, frequent transform and tight connection among data. Only do building enterprises rely on informatization in order to improve management efficiency and achieve the purpose of the performance.

Informatization is the most effective measures to realize the goals and project performance and project benefit. From the start stage, the planning stage, implementation stage to ending stage of the project, informatization can give comprehensive control and forecast to the project time, project cost and project quality. With information means rapid and convenient, added with development and utilization of global positioning system (GPS) and sensing technology (IOT-Internet of Things), intelligent forecasting, analyzing, monitoring and defense can be realized for construction engineering projects. Informatization means can promote the overall development and utilization of information resources and also can realize intelligent monitoring of the construction project management.

Materials, inventory and logistics affect operations for the construction enterprises. At present stage, the influence results mainly from transmission and intelligence analysis of information related to materials, inventory and logistics. Information management will eventually affect the management efficiency and economic benefit. For change of construction schedule and materials and labors, changes of material in locations, consumptions of materials, energy and the logistics costs (including internal logistics handling, labor cost and enterprise overall cost accounting, etc.), it is unable to obtain accurate information and its changes in real time by the traditional mode. Use and development of information resources, which play the role in project management, can accurately and in time reflect change of the variables in the process and provide managers with the basis for scientific decision-making. Basic-level construction enterprises should pay attention to information management at base levels, including logistics, inventory, purchase, the progress of the projects, resource utilization etc., so as to enhance the efficiency of management to work flow.

\section{Influence of Informatization on Management Efficiency}

Planning plays an important role in project management. A complete project plan clearly shows working tasks, 
working ways, executive persons, and finishing time, working place, use of resources, etc. Plan is done by using manual operation in the traditional methods and by informationization means in modern methods. Utilizing information resource in project management can make the project plan be implemented effectively, monitored and tracked, so as to make the project goals be efficiently realized. By informationization, the process of project management will change more systematic. Development and utilization of information resources will carry on analysis and prediction. Especially, the 3D BIM can help you achieve visualization in management and control during construction. The combination of IOT with BIM will lead to a big change of efficiency and benefit for construction enterprise. Informationization can make project management create the following functions:

Real-time following up the progress of the projects is a pressing demand in project management. Time control of construction projects is very strict. The traditional and manual means may make plans, but may not inspect, monitor and track the plan effectively. Besides, because of individuals, plan is delayed step by step while it is being carrying out. The whole project goal should not be achieved as expected. Informationization can real-time reflect project plan and its carrying situation, timely follow-up target, adjust plans and ultimately ensure the task completed as scheduled.

With materials taking for example, in a post of the construction site what type of materials is needed at what time and in how many amount requires exact data message. Planning model in the traditional and manual means cannot achieve such a function. And information related to material required at any post and material inventory is very useful to supervisors and the operators. This information can be captured by information means. Only if the information flows freely and is shared sufficiently, are materials ensured to real-time supply. Excessive or insufficient state for materials will be largely avoided. Construction work process will be in a state of optimization.

The sharing of the information resources is an important means in the cost control for construction projects. As for material purchasing, personnel arrangement, equipment leasing or energy consumption, various aspects of information are collected, sorted and shared. It provides with the reference to scientific decision. Utilization of the resources is maximized and consumption of the resources is reduced to maximum limit. Based on this information, engineering cost controls effectively, so as to save a lot of unnecessary consumption or waste of human, material and financial resources.

Because of the changing environment factors, many uncertain factors exist for the construction project, so as to cause the uncertainty of the project. Based on the shar- ing of information resource, plan technology in project management arranges the project plan in an information system and is in time able to collect, analyze and treat all kinds of information. If so, it also is able to predict the state changes expressed by the information, effectively reduce the uncertainty in the execution process of the project, in order to reduce the project risk and economic loses.

By real-time monitoring quantity, quality and logistics of the materials through information technology, the use of material, the progress of the projects and labor cost can be clearly known. Besides, the technology can make one identify various kinds of hidden troubles, analyze why and when the troubles will happen. Based on the information, one is able to find ways to reduce the consumption of resources, reasonably arrange usage of manpower and material, so as to achieve goal to improve operation efficiency.

Because data record is complete, objective and realtime, the information directly reflects the evaluation on the project quality. Based on this kind of data, performance evaluation to the employee is more reasonable.

Along with the construction market opening, more and more enterprises in our country will step out of the country, in order to participate in the international competition in engineering projects. Information management provides the enterprises with an opportunity at the lower transaction costs and convenient way in communication with customers all over the world, so as to realize the effective process control, cause the enterprise to speed up the operation efficiency and reduce the management cost.

\section{Conclusion}

Based on the analysis to present status of the process control for construction projects, it is pointed out in the paper that the process control affects management efficiency and economic benefit for the enterprises. According to wide development and sufficient utilization of the information resources in various industries, influence of the information management on operation efficiency in the construction industry is discussed and possibility of application of information management in the construction enterprise is analyzed. From the point of view of information resource, the exploration is carried on improving the management efficiency and operating benefit for the construction enterprises.

\section{Acknowledgements}

In the process of the subject research and data analysis, Hu Dejun and Shang Jingyuan, senior engineers both from Tianjin Construction Group, gave their warm support and great help. The author would like to send his heartfelt thanks to them. 


\section{REFERENCES}

[1] C. Q. Xiao, "Study on Application of the Informatization in Construction Enterprise Management," Modern Business, Vol. 12, No. 7, 2010, p. 202.

[2] G. B. Yi and Y. Liu, “Application of Computer Technology in Information Management of Construction Enterprise," Science and Technology Innovation, Vol. 24, No. 9, 2010, pp. 66-67.

[3] P. P. Sun and L. Ye, "Discussion on Project Information Management for Construction Enterprise,” Market Modernization, Vol. 37, No. 8, 2008, p. 86.

[4] X. Q. Zhang and Y. W. Zheng, "Research and Application of Information Technology in Construction Corporation,” Construction Technology, Vol. 13, No. 12, 2001, pp. 7-9.

[5] C. X. Yang, "Discussion on Strengthening Information Management for Construction Enterprises," Shanxi Construction, Vol. 36. No. 13, 2010, pp. 200-201.

[6] J. P. Zhang and T. Y. Ma, "Information Technology in the Strategic Management of Construction Corporations," China Civil Engineering Journal, Vol. 45, No. 12, 2004, pp. 81-86.

[7] H. K. Zhang, "Discussion on Problems and Solutions for Construction Enterprise Management,” Manager' Journal, Vol. 19, No. 15, 2012, p. 97.

[8] L. F. Shen and Y. Ren, "New Tool of Innovation for Construction Enterprise Management,” Construction Enterprise Management, Vol. 27, No. 11, 2012, pp. 83-84.

[9] K. Zhang and Z. Li, "Research on Software Integration Based on BIM Construction Information Management," Construction Quality, Vol. 30, No. 10, 2012, pp. 9-12.

[10] C.-Y. Wang, Q. Liu and J.-P. Wang, "Analysis of Impact Factors of Knowledge Management for Construction En- terprises,” Journal of Engineering Management, Vol. 24, No. 1, 2010, pp. 96-101.

[11] Y. F. Mei, "Innovation and Thinking about Construction Enterprise Management," Foreign Investment in China, Vol. 11, No. 18, 2011, p. 128.

[12] R. Y. Hu, “Analysis on Management Informatization for Construction Enterprise,” Information of China Construction, Vol. 18, No. 22, 2012, pp. 52-55.

[13] B. M. Yang, "Building Information Model and Enterprise Resource Plan,” Construction Technology, Vol. 37, No. 6, 2008, pp. 31-33.

[14] C. X. Zhang, "Study on Application Situation and Development Barriers of BIM in China Construction Industry," Construction Economy, Vol. 32, No. 9, 2011, pp. 96-98.

[15] T. H. Li, Y. B. Yuan and M. Y. Zhang, "BIM and RFID Assisted Life Cycle Management of Prefabricated Buildings,” Journal of Engineering Management, Vol. 26, No. 3, 2012, pp. 28-32.

[16] J. R. Wang, "To Strengthen Process Control for the Quality of Concrete Construction," Architectural Design Management, Vol. 27, No. 5, 2010, pp. 74-76.

[17] S. J. Zhao and L. Wang, "Problems Existing in the Engineering Management for Construction and the Counter Measures," Heilongjiang Science and Technology Information, Vol. 15, No. 10, 2011, p. 230.

[18] J. Y. Chen, "Discussion on Innovation about the Project Construction Management,” Guangdong Science \& Technology, Vol. 20, No. 6, 2011, pp. 103-104.

[19] L. L. Shi, "Research on Construction Site Management for Construction Projects,” Inner Mongolia Science \& Technology and Economy, Vol. 30, No. 4, 2011, pp. 50-52. 